\title{
Originals
}

\section{Islet amyloid polypeptide in the rabbit and European hare: studies on its relationship to amyloidogenesis}

\author{
L. Christmanson ${ }^{1,3}$, C. Betsholtz ${ }^{1}$, A. Leckström ${ }^{3}$, U. Engström $^{2}$, C. Cortie $^{3}$, \\ K.H.Johnson ${ }^{5}$, T. E. Adrian ${ }^{4}$ and P. Westermark ${ }^{3}$ \\ ${ }^{1}$ Department of Pathology, University of Uppsala, \\ ${ }^{2}$ Ludwig Institute of Cancer Research, Uppsala Branch, Uppsala, ${ }^{3}$ Department of Pathology, University of Linköping, Linköping, Sweden, \\ ${ }^{4}$ Department of Biomedical Sciences, School of Medicine, Creighton University, Omaha, Nebraska and \\ ${ }^{5}$ Department of Veterinary PathoBiology, University of Minnesota, St. Paul, Minnesota, USA
}

\begin{abstract}
Summary. In this study, we determined the cDNA-predicted amino acid sequence of positions 9-31 of islet amyloid polypeptide from the rabbit and European hare. A synthetic rabbit/hare islet amyloid polypeptide 20-29 peptide was subsequently shown to be strongly fibrillogenic in vitro even though the putative amyloidogenic AILS sequence at positions 25-28 of human and cat islet amyloid polypeptide is modified in the rabbit and hare by a substitution of phenylalanine for leucine at position 27 (i.e. AIFS). Although islet amyloid polypeptide of both the rabbit and hare has an amyloidogenic sequence and is in fact amyloidogenic in vitro, the apparent lack of in vivo islet amyloidosis in rabbits and hares may be related to relatively low levels of islet amyloid poly-
\end{abstract}

peptide production by the islet beta cells in these species. This was supported by our findings that there is no substantial immunoreactivity in either rabbit or hare islets, and no measurable amount either in extracts of rabbit pancreases, or in rabbit plasma. This study supports the need for at least two prerequisites for the development of islet amyloidosis in vivo: an inherent fibrillogenic sequence within the islet amyloid polypeptide molecule and an adequate local concentration of islet amyloid polypeptide to promote self aggregation and formation of islet amyloid.

Key words: Islet amyloid polypeptide, polymerase chain reaction, amyloid fibril, pancreas, Lagomorpha, cDNA.
Amyloid deposits associated with insulinomas and the pancreatic islets of species (e.g., humans, cats, and non-human primates) that develop age-associated diabetes mellitus have recently been shown to represent a concentrated and polymerized form of a previously unknown islet-derived polypeptide identified either as islet amyloid polypeptide (IAPP) or amylin [1-3]. IAPP, a highly conserved and carboxy-terminally amidated 37 amino acid polypeptide with approximately $45 \%$ amino acid sequence identity to calcitonin gene-related peptide (CGRP), is produced by islet beta cells and is co-localized with insulin in beta-cell secretory vesicles [4-6]. IAPP is secreted biphasically and in parallel with insulin in response to glucose and other secretagogues [7-9]. There is also some evidence of extrapancreatic production of IAPP, but islet beta cells are the predominant source of IAPP [10]. This is consistent with its only known site of in vivo amyloid deposition.

Although all forms of amyloid are characterized by certain common features (e.g. protein fibrils with significant beta-pleated sheet conformation and congophilia), quite specific and different pathogenetic mechanisms are probably associated with each of the chemically distinct forms of amyloid [11]. The factors and mechanisms demonstrated to-date to be involved in the formation of IAPP- derived amyloid deposits have been generated from a number of comparative studies of IAPP from multiple animal species and humans. These studies of IAPP in multiple primate, carnivore and rodent species (i.e. human, non-human primates, cat, dog, hamster, guinea pig, mouse, rat, and degu) [12-21] have shown that the amyloidogenicity of IAPP in certain mammalian species $[11,14,22]$ is importantly related to the amino acid residues inherently found in the 20-29 region of IAPP from those species $[13,14,23]$. The amino acids at positions 25-28 (alanine-isoleucine-leucine-serine: AILS) of human and cat IAPP are identical and appear to be the most important amyloidogenic sequences common to the human and cat [23]. In vivo fibrillogenesis studies have shown that single amino acid substitutions in this region especially decrease the amyloidogenicity of IAPP [23]. Studies in dogs and cats additionally suggest that aberrations in beta-cell synthesis (or processing) of IAPP may lead to an increased concentration of IAPP in the local milieu, thus providing a second prerequisite for the self-aggregation of IAPP to form islet amyloid in those species with the amyloidogenic IAPP sequence [24, 25].

In the present study we extend our comparative studies of IAPP to two lagomorphs, the rabbit (Oryctolagus cu- 


\section{Hare CACACAACGCCTGGCAAATTTTTTAATTCATTCCAGCAACAACTTTT \\ Rabbit \\ Human

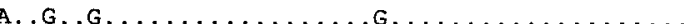 \\ Hare GGTGCCATTTPCTCACCTCCCAAT \\ Rabbit $\quad \ldots \ldots \ldots \ldots \ldots \ldots \ldots$ GC \\ Human $\quad$.................}

Fig. 1. cDNA sequences corresponding to amino acid positions 9-31 of European hare, rabbit and human IAPP

niculus) and European hare (Lepus europaeus) to provide further documentation of the factors that are probably involved in the fibrillogenesis of IAPP. Previously demonstrated amyloidogenic IAPP sequences have been restricted to primates and carnivores. Utilizing molecular biology, immunochemistry, and immunohistochemistry we show that although IAPP of lagomorphs has an amyloidogenic sequence and is in fact amyloidogenic in vitro the apparent lack of in vivo development of islet amyloidosis in rabbits and hares may be related to a low level of IAPP production by the islet beta cells.

\section{Materials and methods}

\section{Tissues}

The pancreas of a New Zealand White rabbit was removed directly after killing and pieces were immediately frozen at $-70^{\circ} \mathrm{C}$ for subsequent isolation of RNA. The pancreas of a wild European hare was removed within $30 \mathrm{~min}$ after being shot and was also frozen as above.

Small pieces (representing head, tail and mid-region) from the pancreases of the hare and rabbit above were also fixed in $10 \%$ neutral buffered formalin and embedded in paraffin for immunohistochemical analysis. Samples of the same regions of pancreas from six additional New Zealand White rabbits were fixed in $10 \%$ neutral buffered formalin for immunohistochemistry.

\section{Rabbit and hare cDNA}

Standard recombinant DNA methods were generally applied [26]. Total RNA (to be used in both cDNA synthesis and Northern blot hybridisation) was prepared from the pancreases of a rabbit and a hare by the LiCl/urea [27] and guanidinium isothiocyanate methods [28] followed by chromatography on oligo(dT)-cellulose columns. The RNA appeared to be intact as judged from agarose gel electrophoresis and ethidium bromide staining using both methods. The oligonucleotide primers used in the polymerase chain reaction (PCR) were 5'ATTCGAGAATTCTGCAACAC $(\mathrm{G} / \mathrm{T}) \mathrm{GCCAC}$ (G/A)TGTGC and 5'ATTCGAGGATCC(G/A)TA(C/T)GT (G/A)TT(C/G)GATCCCAC (redundant positions in parentheses), corresponding to positions $1-7$ and 32-37, respectively, in the human IAPP amino acid sequence. For first strand cDNA synthesis a cDNA synthesis kit (Amersham International, Bucks, UK) was used following the manufacturer's instructions. Approximately $20 \mathrm{ng}$ of the resulting cDNA was used together with 120 picomoles of each oligonucleotide primer in high stringent PCR (30 amplification cycles with annealing at $60^{\circ} \mathrm{C}$, elongation at $72^{\circ} \mathrm{C}$ and denaturation at $95^{\circ} \mathrm{C}$ ). The amplified product was run on a $3 \%$ agarose-TBE-gel revealing a single band of expected size (134 nucleotides). This fragment was purified by isotachophoresis [29], kinased and subcloned in M13 sequencing vectors. Several clones were sequenced [30] in order to avoid PCR artefacts. Northern blot analysis was performed according to standard protocols [26].

\section{Synthetic fibrils and fibrillogenesis in vitro}

Carboxy-terminally amidated peptides corresponding to positions 20-29 and 20-30 of the rabbit/hare IAPP molecule, as determined by cDNA analysis (Fig. 1), were synthesized by automatic solid-phase synthesis on a model 430A peptide synthesizer (Applied Biosystems, Foster City, Calif., USA). Additionally, carboxy-terminally amidated peptides corresponding to positions 26-37 of human IAPP and a hybrid IAPP 26-37 (with Phe-27, Pro-29, Pro-30, Ser-31) were synthesized using the same methods. The latter hybrid peptide includes the rabbit/hare sequence from positions 26 through 31 and the highly conserved carboxy-terminal amino acid residues present in humans and other species from positions 32 through 37 .

The ability of these peptides to form amyloid-like fibrils in vitro was tested using previously described procedures [23]. Briefly, the peptides were dissolved $(10 \mathrm{mg} / \mathrm{ml})$ in $10 \%$ acetic acid and left at room temperature for $24 \mathrm{~h}$. The presence of fibrils was then evaluated in a Jeol $2000 \mathrm{C}$ electron microscope after negative staining ( $1 \%$ uranyl acetate) of dried material obtained either directly from the acidic solution or after neutralization with $\mathrm{NH}_{4} \mathrm{OH}$. Dried smears on glass slides were stained with alkaline Congo red and evaluated with a polarized light source for green birefringence, which is a characteristic feature of amyloid.

\section{Immunohistochemical methods}

Rabbit antisera to syn thetic human $\mathrm{IAPP}_{7-17}$ and $\mathrm{IAPP}_{20-29}$ have been characterized previously $[2,5]$. Antisera to rat IAPP $_{1-37}$ (AA110) and human $\mathrm{IAPP}_{1-37}$ (AA116) were raised in two rabbits by standard methods using synthetic rat IAPP (purchased from Multiple Peptide Systems, San Diego, Calif., USA) and synthetic human IAPP [31] which were linked to keyhole limpet haemocyanin [5]. When used in immunohistochemistry on pancreatic sections from human, cat and rat, both antisera AA110 and AA116 labelled islet beta cells specifically and strongly. This reaction was abolished when the antisera were preabsorbed $(10 \mathrm{mg} / \mathrm{ml}$ of undiluted antiserum) with rat and human IAPP ${ }_{1-37}$, respectively. Antiserum to porcine insulin, raised in a guinea pig (Ma37), has been described previously [32].

For immunohistochemistry [33], the peroxidase-antiperoxidase (PAP) method was used with linking antibody and peroxidaseantiperoxidase complex from Dako (Copenhagen, Denmark). Deparaffinized pancreatic sections were incubated with the primary antiserum diluted 1:200, 1:400 and 1:800. Immunoreaction was visualized with diaminobenzidine.

\section{Radioimmunoassay}

For determination of the pancreatic content of IAPP, pancreases from six rats and six rabbits were collected after killing and immediately frozen on dry ice. The animals had been fed ordinary laboratory diets ad libitum. Plasma samples for detection of IAPP were extracted on C-18, reversed phase Sep-Pak cartridges, using multichannel syringe ram pumps (Harvard Instruments, Southnatic, Mass., USA). After washing, the Sep-Paks were eluted with $3 \mathrm{ml}$ $60 \%$ acetonitrile with $0.1 \%$ trifluoroacetic acid. The recovery of added IAPP at concentrations of 10 and $30 \mathrm{fmol} / \mathrm{ml}$ are approximately $60 \%$. These eluates were lyophilized and reconstituted in assay buffer $(60 \mathrm{mmol} / \mathrm{l}$ phosphate, $\mathrm{pH} 7.4$ with $0.1 \%$ Triton-X 100 and $0.1 \%$ bovine serum albumin) prior to assay. Tissue samples for IAPP extraction, were weighed and, while still frozen, plunged into a tube of boiling $0.5 \mathrm{~mol} / 1$ acetic acid $(10 \mathrm{ml} / \mathrm{g}$ wet weight) in a vigorously boiling water bath for $10 \mathrm{~min}$. Extracts were assayed in duplicate at dilutions equivalent to $0.1,1$ and $10 \mu \mathrm{l} / \mathrm{tube}$. 


\begin{tabular}{|c|c|c|c|}
\hline & 20 & & \\
\hline Human & TQRLANFLVHSSNNFGAILSSTN & (15, & 20) \\
\hline Monkey & $--------\mathrm{R}-\cdots---\mathrm{T}-\cdots---$ & (21) & \\
\hline Cat & $---\cdots--I R----\mathrm{L}----\mathrm{P}--$ & (13) & \\
\hline Dog & $---------\mathrm{RT}---\mathrm{L}-----\mathrm{P}--$ & (21, & 35) \\
\hline Rat & $---------\mathrm{R}----\mathrm{L}-\mathrm{PV}-\mathrm{PP}--$ & $(12$, & $14,17)$ \\
\hline Hamster & $---------N--\mathrm{L}-\mathrm{PV}--\mathrm{P}--$ & (14) & \\
\hline Guinea pig & $----\mathrm{T}----\mathrm{R}--\mathrm{H}-\mathrm{L}--\mathrm{A}-\mathrm{L} \mathrm{P}-\mathrm{D}$ & (19) & \\
\hline Degu & $---\mathrm{T}---\mathrm{R}--\mathrm{H}-\mathrm{L}--\mathrm{A}-\mathrm{PP}-\mathrm{K}$ & (20) & \\
\hline Rabbit & $--------\mathrm{I}---------\mathrm{F}-\mathrm{PPS}$ & (This & paper) \\
\hline Hare & $\cdots-\cdots-\cdots-\cdots-P P-$ & (This & paper) \\
\hline
\end{tabular}

Fig.2. Amino acid sequences of IAPP $_{9-31}$ of species belonging to the four different mammalian orders primates (human and macaque), carnivores (cat and dog), lagomorphs (rabbit and hare) and rodents (rat, hamster, guinea pig and degu)

A commercial antiserum against IAPP ( \# RAS7321, Peninsula, Merseyside, UK) was used for radioimmunoassay. This antiserum measures both rat and human IAPP, but shows negligible cross-reactions with CGRP (human CGRP I: $<0.001 \%$, rat CGRP I: $<0.1 \%$, human and rat CGRP II: undetectable). For tracer, rat IAPP labelled with Bolton and Hunter reagent (\# IM.234, Amersham) was used. This labelled IAPP has a specific activity of $74 \mathrm{~Bq} / \mathrm{fmol}$. Samples were set up in duplicate tubes containing $0.5 \mathrm{ml} 60 \mathrm{mmol} / \mathrm{l}$ phosphate buffer, $\mathrm{pH} 7.4$ with $0.1 \%$ Triton-X 100 and $0.1 \%$ bovine serum albumin. The antiserum was added at a final dilution of 1:500,000, which bound approximately $50 \%$ of 1 fmol of tracer. The assay detects changes between adjacent samples of $0.2 \mathrm{fmol}$ IAPP per tube with $95 \%$ confidence (equivalent to $1 \mathrm{pmol} / \mathrm{l}$ plasma). Intra-assay and inter-assay variations are below $8 \%$ and $14 \%$ respectively, measured at 5 and $15 \mathrm{fmol} / \mathrm{ml}$.

\section{Results}

\section{Rabbit and hare IAPP cDNA sequences}

The sequences of rabbit and hare IAPP (corresponding to amino acid positions $9-31$ ) as predicted by cDNA analysis are shown in Figure 1. The rabbit and hare sequences differed in only two nucleotide positions, both corresponding to position 31 in the amino acid sequence. These nucleotide differences result in serine in position 31 of rabbit IAPP and asparagine in position 31 of hare IAPP. Comparison of the deduced amino acid sequences of IAPP $_{9-31}$ of the rabbit and hare with representatives from three other mammalian orders (Fig. 2) reveals considerable differences between the IAPP sequences of the two lagomorphs and the other species. The number of amino acid differences between the species is shown in Table 1 . Two amino acid substitutions are unique for the lagomorphs, namely phenylalanine in position 27 and proline in position 30 . The latter variation in the lagomorph sequence is within an otherwise conserved part of the IAPP molecule.

Northern blot analysis of both the rabbit and hare pancreas showed a single abundant IAPP transcript of approximately 0.8 kilo base (Fig. 3 ).

\section{Islet amyloid polypeptide in the pancreas of lagomorphs}

Using the PAP procedure and four different antisera to IAPP, no immunoreactivity was observed in pancreatic islets of any of the seven rabbits and one hare. Evidence of IAPP immunoreactivity was even lacking when antiserum to the conserved 7--17 segment of IAPP was used. In contrast, islets from both the hare and rabbit reacted strongly with the antiserum to insulin.

The content of IAPP in the rat pancreases as determined by RIA was $285 \pm 13$ (mean \pm SEM) pmol/g wet weight. In marked contrast, the pancreas of each of six rabbits contained undetectable levels of IAPP.

Mean plasma IAPP levels as measured by RIA in six rats were $32 \pm 3 \mathrm{pmol} / 1$, while IAPP in plasma was not detectable in any of the six rabbits studied.

\section{Fibrillogenesis of synthetic lagomorph IAPP in vitro}

Rabbit/hare IAPP $_{20-29}$ showed a strong tendency (comparable to that of human $\operatorname{IAPP}_{20-29}$ ) to form amyloid-like fibrils in acidic solution. These fibrils, which consisted of very thin parallely-attached filaments, were long, wavy and non-branching. The fibrils, which usually measured about $8 \mathrm{~nm}$ in width (Fig. 4), had strong affinity for Congo red dye and illicited bright green birefringence when Congo red-stained preparations were examined with polarized light. Rabbit/hare IAPP $20-30$ gave rise to very few amyloid-like fibrils in acidic solution but was converted more or less completely to fibrils when the solution was neutralized.

Both synthetic human IAPP $26-37$ and the synthetic hybrid IAPP $26-37$ (containing the rabbit/hare sequence at positions 26-31) gelled and formed amyloid-like fibrils, but only after neutralization of the acidic solution. These amyloid-like fibrils had morphological characteristics identical with those described for the other synthetic peptides in this study (not shown).

Table 1. Identity of IAPP (9-31) between different mammalian species. The numbers of differences between species are given

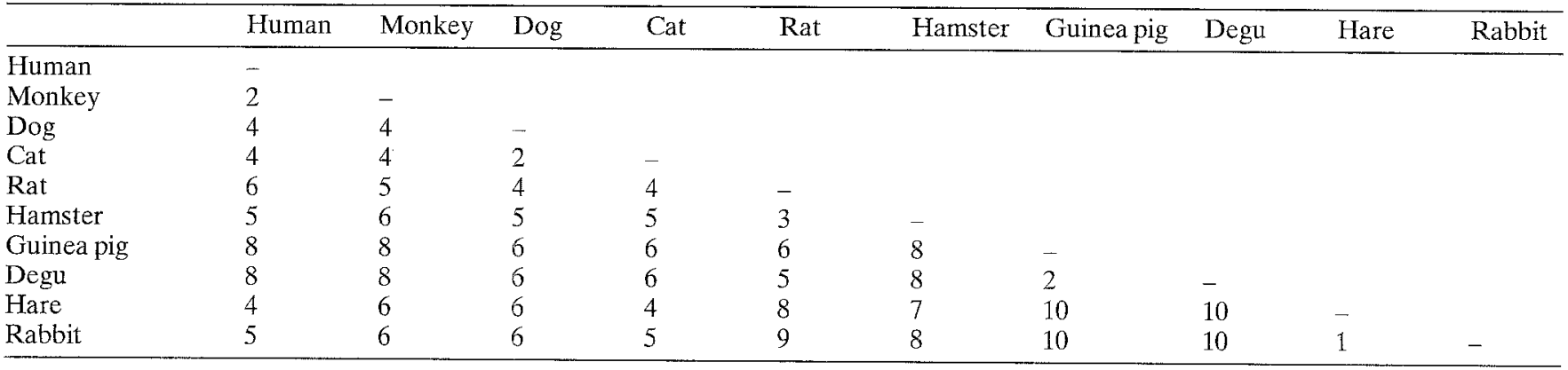




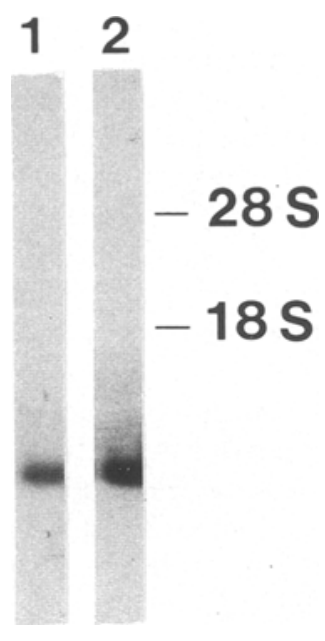

Fig. 3. Expression of IAPP in the pancreas of rabbit (lane 1) and European hare (lane 2) analysed by Northern hybridization. Ten microgrammes of total RNA were applied for each lane

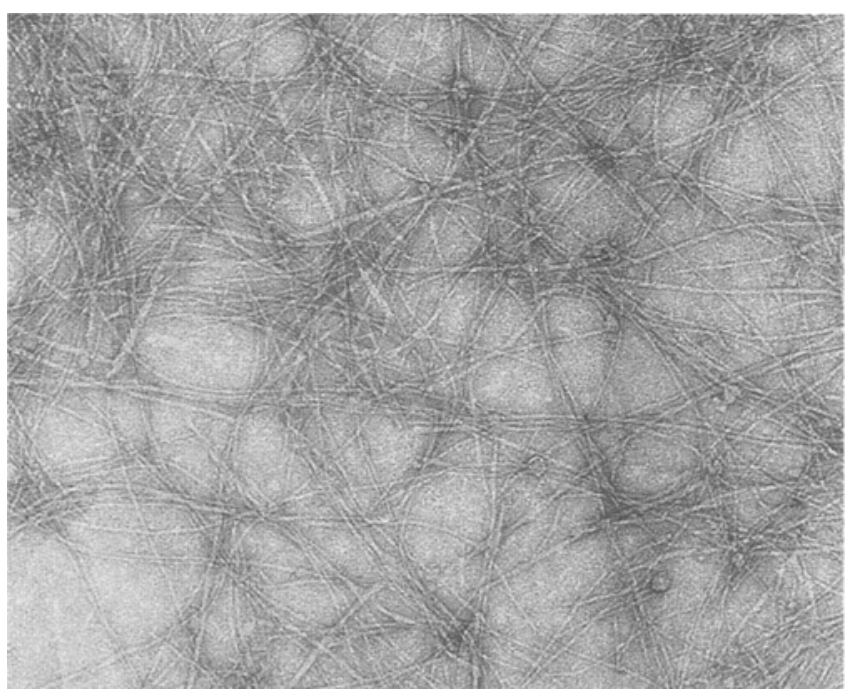

Fig.4. Amyloid-like fibrils obtained with a synthetic decapeptide corresponding to rabbit/hare IAPP, positions 20-29. Negatively contrasted with uranyl acetate, magnification $\times 65,000$

\section{Discussion}

The discovery of IAPP as the precursor protein for amyloid deposited in insulinomas and pancreatic islets, together with the accumulating evidence of the hormonal nature of IAPP, have heightened the likelihood that islet amyloid deposits are an important reflection of beta-cell dysfunction in some phase of the pathogenesis of Type 2 (non-insulin-dependent) diabetes $[11,34]$. Although the normal physiological action(s) of IAPP are yet to be verified, and the specific role(s) of IAPP in the progression of Type 2 diabetes are yet to be clarified, increased production and secretion of IAPP have been implicated as important factors in both the islet amyloidogenesis and the development of Type 2 diabetes.

Although IAPP production and secretion by islet beta cells has been demonstrated in humans and numerous animal species, it is well known from studies over the past 20 years that islet amyloid deposits occur in only a very few species (i.e. humans, non-human primates, cats, raccoons, and degus). Studies of IAPP from multiple animal species and humans have provided a growing body of information that has provided important clues that help to explain the development of IAPP-derived islet amyloid [34].

In addition to the primary structure of IAPP, increased synthesis and thus increased concentration of IAPP in the local milieu of the islets has also been proposed as a second prerequisite for the amyloidogenesis of IAPP [24]. This is indirectly supported by the observation that although the cDNA-predicted sequence of dog IAPP includes the same putative amyloidogenic sequence (AILS at positions 25-28) as human and cat, the occurrence of islet amyloid in dogs has never been confirmed [35]. However, we have shown that IAPP forms islet amyloid deposits in dog insulinomas [25]. We have also found that the beta cells of normoglycaemic cats with impaired glucose tolerance have increased IAPP immunoreactivity, and that these cats have a much higher incidence of IAPPderived islet amyloid as compared to normal age-matched cats [24]. Interestingly, there is hypersecretion of IAPP in glucose-intolerant first-degree relatives of patients with Type 2 diabetes [36].

Our study of IAPP and IAPP-amyloidogenesis in lagomorphs was stimulated by observations from our ongoing comparative studies of IAPP in multiple animal species. Most specifically, we were curious about our inability to demonstrate any significant IAPP immunoreactivity in the pancreatic islets of the rabbit. We considered the possibility that there are considerable IAPP sequence differences that explain these immunohistochemical observations, and also raised the question of whether IAPP is present in rabbit islets. In this study, we also included cDNA and immunohistochemical analysis of a pancreas from a hare to determine if there are sequential features typical of lagomorphs which accounted for our initial observations in rabbits. For PCR amplification of the respective cDNAs, we chose to use primers corresponding to the amino- and carboxyterminal regions of IAPP which are highly conserved in all other species studied $[13,19]$. This approach was used in that the flanking prolAPP peptides have considerable interspecies variation [19].

The deduced amino acid sequence of IAPP of rabbit and hare $\mathrm{IAPP}_{9-31}$ differs from the human in only five and four positions, respectively. It is unlikely that sequence differences explain the lack of any substantial IAPP immunoreactivity in islets of the multiple lagomorphs studied and the lack of measurable IAPP levels in extracts of rabbit pancreases and in plasma since antihuman $\mathrm{IAPP}_{7-17}$ reacts strongly with cat IAPP [4], which is identical with the hare and rabbit IAPP in the 9-17 region. Likewise, the IAPP $_{26-37}$ hybrid (containing the rabbit/hare sequence at positions 26-31) reacts strongly with three different IAPP antisera in RIA and ELISA (unpublished result). The lack of any substantial IAPP immunoreactivity appears more likely to be related to a relatively low content of this polypeptide in lagomorph islets and plasma. Interestingly, Northern blot analyses of rabbit and hare pancreatic RNA indicated abundant IAPP mRNA in the lagomorph islets. Therefore, it is possible that the translation of mRNA to IAPP in lagomorphs is low. 
We have also shown in this study that synthetic rabbit/hare $\mathrm{IAPP}_{20-29}$ is strongly fibrillogenic in vitro even though the putative amyloidogenic AILS sequence at positions $25-28$ of human and cat IAPP is modified by a substitution of phenylalanine for leucine at position 27 (i.e. AIFS). The presence of the proline residue in position 30 of synthetic rabbit/hare IAPP $_{20-30}$ diminished the fibrilforming capacity of hare/rabbit IAPP $20-30$ in acidic solution but marked fibrillogenesis was apparent when the solution was neutralized. Although we have not studied the in vitro fibrillogenesis of full-length rabbit/hare IAPP, both synthetic human $\mathrm{IAPP}_{26-37}$ and a synthetic hybrid $\mathrm{IAPP}_{26-37}$ formed amyloid-like fibrils after neutralization.

These findings regarding IAPP in lagomorphs generally appear to be comparable with observations concerning $\operatorname{dog}$ IAPP, thus supporting the need for at least two prerequisites for the development of islet amyloidosis. Although inherently amyloidogenic sequences exist in both lagomorph and dog IAPP, there appears to be a low expression of IAPP by islet beta cells and (as a result) lack of any evidence of IAPP-derived islet amyloidosis in these animals. The apparent lack of islet amyloidosis in lagomorphs is supported by the absence of any documentation of islet amyloidosis in lagomorphs in the literature [37], and also by our own survey of case materials extending over a 20-year period at the College of Veterinary Medicine, University of Minnesota.

Examination of the deduced amino acid sequences [12-21] of $\mathrm{IAPP}_{9-31}$ of representatives of four different mammalian orders (primates: human and macaque; carnivores: dog and cat; rodents: rat, hamster, guinea pig and degu; and lagomorphs: European hare and rabbit) indicate that the biggest differences are found between lagomorphs and rodents. It is also noticeable that there are several differences between the representatives of the two rodent suborders myomorpha (rat and hamster) and hystricomorpha (guinea pig and degu). This difference is as pronounced as between the different orders and could support the suggestion that hystricomorpha is a separate order [38].

Acknowledgements. This work was supported by the Swedish Medical Research Council and the Nordic Insulin Fund. We thank Mr. C. Bergman for providing the hare pancreas used in this study.

\section{References}

1. Westermark P, Wernstedt C, Wilander E, Sletten K (1986) A novel peptide in the calcitonin gene related peptide family as an amyloid fibril protein in the endocrine pancreas. Biochem Biophys Res Commun 140: 827-831

2. Westermark P, Wernstedt C, Wilander E, Hayden DW, O'Brien TD, Johnson KH (1987) Amyloid fibrils in human insulinoma and islets of Langerhans of the diabetic cat are derived from a neuropeptide-like protein also present in normal islet cells. Proc Natl Acad Sci USA 84:3881-3885

3. Cooper GJ, Willis AC, Clark A, Turner AC, Sim RB, Rei KB (1987) Purification and characterization of a peptide from amyloid-rich pancreases of type 2 diabetic patients. Proc Natl Acad Sci USA 84: 8628-8632

4. Johnson K, O'Brien TD, Hayden DW et al. (1988) Immunolocalization of islet amyloid polypeptide (IAPP) in the pancreatic beta cells by means of peroxidase-antiperoxidase (PAP) and protein A-gold techniques. Am J Path 130: 1-8

5. Lukinius A, Wilander E, Westermark GT, Engström U, Westermark P (1989) Co-localization of islet amyloid polypeptide and insulin in the B cell secretory granules of the human pancreatic islets. Diabetologia 32: 240-244

6. Clark A, Edwards CA, Ostle LR et al. (1989) Localization of islet amyloid peptide in lipofuscin bodies and secretory granules of human $\beta$-cells and in islets of type- 2 diabetic subjects. Cell Tissue Res 259: 179-185

7. Mitsukawa T, Takemura J, Asai J (1990) Islet amyloid polypeptide response to glucose, insulin, and somatostatin analogue administration. Diabetes 39: 639-642

8. Ogawa A, Harris V, McCorkle SK, Unger RH, Luskey KL (1990) Amylin secretion from the rat pancreas and its selective loss after streptozotocin treatment. J Clin Invest 85: 973-976

9. Kahn SE, D'Alessio DA, Schwartz MW et al. (1990) Evidence of cosecretion of islet amyloid polypeptide and insulin by $\beta$-cells. Diabetes 39: 634-638

10. Asai J, Nakazato M, Miyazato M, Kangawa K, Matsuo H, Matsukura S (1990) Regional distribution and molecular forms of rat islet amyloid polypeptide. Biochem Biophys Res Commun 169: 788-795

11. Westermark P, Johnson KH (1988) The polypeptide hormonederived amyloid forms: nonspecific alterations or signs of abnormal peptide-processing? APMIS 96: 475-483

12. Asai J, Nakazato M, Kangawa K, Matsukura S, Matsuo H (1989) Isolation and sequence determination of rat islet amyloid polypeptide. Biochem Biophys Res Commun 164: 400-405

13. Betsholtz C, Christmanson L, Engström U et al. (1990) Structure of cat islet amyloid polypeptide and identification of amino acid residues of potential significance for islet amyloid formation. Diabetes 39: 118-122

14. Betsholtz C, Christmanson L, Engström U (1989) Sequence divergence in a specific region of islet amyloid polypeptide (IAPP) explains differences in islet amyloid formation between species. FEBS Lett 251: 261-264

15. Betsholtz C, Svensson V, Rorsman F et al. (1989) Islet amyloid polypeptide (IAPP): cDNA cloning and identification of an amyloidogenic region associated with the species-specific occurrence of age-related diabetes mellitus. Exp Cell Res 183:484 493

16. Johnson KH, Wernstedt C, O'Brien TD, Westermark P (1991) Amyloid in the pancreatic islets of the cougar (Felis concolor) is derived from islet amyloid polypeptide (IAPP). Comp Biochem Physiol 98B: 115-119

17. Leffert JD, Newgard CB, Okamoto H, Milburn JL, Luskey KL (1989) Rat amylin: cloning and tissue-specific expression in pancreatic islets. Proc Natl Acad Sci USA 86: 3127-3130

18. Mosselman S, Höppener JWM, Lips CJM, Jansz HS (1989) The complete islet amyloid polypeptide precursor is encoded by two exons. FEBS Lett 247: 154-158

19. Nishi M, Chan SJ, Nagamatsu S, Bell GI, Steiner DF (1989) Conservation of the sequence of islet amyloid polypeptide in five mammals is consistent with its putative role as an islet hormone. Proc Natl Acad Sci USA 86: 5738-5742

20. Nishi M, Sanke T, Nagamatsu S, Bell GI, Steiner DF (1990) Islet amyloid polypeptide. A new $\beta$ cell secretory product related to islet amyloid deposits. J Biol Chem 265: 4173-4176

21. Ohagi S, Nishi M, Bell GI, Ensinck JW, Steiner DF (1991) Sequences of islet amyloid polypeptide precursors of an old world monkey, the pig-tailed macaque (Macaca nemestrina) and the $\operatorname{dog}$ (Canis familiaris). Diabetologia 34: 555-558

22. Clark A, Morris JF, Scott LA et al. (1991) Intracellular formation of amyloid fibrils in B-cells of human insulinoma and prediabetic monkey islets. In: Natvig JB, Förre $\ddot{O}$, Husby $G$ et al. (eds) Amyloid and amyloidosis 1990. Kluwer, Dordrecht, pp 453-456

23. Westermark P, Engström U, Johnson KH, Westermark GT, Betsholtz C (1990) Islet amyloid polypeptide: pinpointing amino acid residues linked to amyloid fibril formation. Proc Natl Acad Sci USA 87: 5036- 5040 
24. Johnson KH, O’Brien TD, Jordan K, Westermark P (1989) Impaired glucose tolerance is associated with increased islet amyloid polypeptide (IAPP) immunoreactivity in pancreatic beta cells. Am J Pathol 135: 245-250

25. O'Brien TD, Westermark P, Johnson KH (1990) Islet amyloid polypeptide and calcitonin gene-related peptide immunoreactivity in amyloid and tumor cells of canine pancreatic endocrine tu mors. Vet Pathol 27: 194-198

26. Sambrook J, Fritsch EF, Maniatis T (1989) Molecular cloning, 2nd edn. Cold Spring Harbor Laboratory Press, Cold Spring Harbor, N.Y.

27. Auffrey JC, Rougeon F (1980) Purification of mouse immunoglobulin heavy chain-messenger RNA's from total myeloma tumor RNA. Eur J Biochem 107: 303-314

28. Chomazynski P, Sacchi N (1987) Single-step method of RNA isolation by acid guanidinium thiocyanate-phenol-chloroform extraction. Analyt Biochem 162: 156-159

29. Öfverstedt L-G, Hammarström K, Balgobin N, Hjertén S, Pettersson U, Chattopadyaya J (1984) Rapid and quantitative recovery of DNA-fragments from gels by displacement electrophoresis (isotachophoresis). Biochim Biophys Acta 782: 120-126

30. Sanger F, Nicklen S, Coulson AR (1977) DNA sequencing with chain-terminating inhibitors. Proc Natl Acad Sci USA 74: 54635467

31. Zierath JR, Galuska D, Engström $\AA$ et al. (1992) Human islet amyloid polypeptide at pharmacological levels inhibits insulin and phorbol ester-stimulated glucose transport in in vitro incubated human muscle strips. Diabetologia 35: 26-31

32. Westermark $P$, Wilander $E$ (1983) Islet amyloid in type 2 (non-in sulin-dependent) diabetes is related to insulin. Diabetologia 24: $342-346$
33. Sternberger LA (1979) Immunocytochemistry, 2nd edn, Wiley, New York

34. Westermark P, Johnson KH, O'Brien TD, Betsholtz C (1992) Islet amyloid polypeptide - a novel controversy in diabetes research. Diabetologia 35: 297-303

35. Jordan K, Murtaugh MP, O'Brien TD, Westermark P, Betsholtz C, Johnson KH (1990) Canine IAPP cDNA sequence provides important clues regarding diabetogenesis and amyloidogenesis in type 2 diabetes. Biochem Biophys Res Commun 169: 502-508

36. Eriksson J, Nakazato M, Miyazato M, Shiomi K, Matsukura S, Groop L (1992) Islet amyloid polypeptide plasma concentrations in individuals at increased risk of developing type 2 (non-insulindependent) diabetes mellitus. Diabetologia 35:291-293

37. Zschiesche W, Jakob W (1989) Pathology of animal amyloidoses. Pharm Ther 41: 49-83

38. Graur D, Hide WA, Li W-H (1991) Is the guinea-pig a rodent? Nature 351: 649-652

Received: 5 October 1992

Prof. P. Westermark

Faculty of Health Sciences

Department of Pathology

S-581 85 Linköping

Sweden 